\title{
A LITERATURA INFANTIL FORA DO LIVRO: JORNAL O SENHOR DOUTOR E A REVISTA TICO-TICO
}

\section{Lígia R Máximo Cavalari Menna ${ }^{1}$}

RESUMO: Houve um tempo em que a literatura e jornalismo caminhavam juntos e textos literários podiam ser encontrados em diversas publicações. Há vários estudos quanto à relação entre esses campos, suas confluências e divergências, seus produtores e seus leitores. Contudo, quando o assunto é a literatura destinada ao público infantil, pouco foi discutido. Essa é uma lacuna a ser preenchida, uma vez que há um vasto material a ser analisado. Neste artigo, propomo-nos a apresentar o início de nossas pesquisas para o doutorado, expondo as primeiras considerações a respeito da literatura infantil fora do livro, em meados do século IXX e primeiras décadas do século XX, dando destaque à revista brasileira O Tico-Tico e ao jornal português O Senhor Doutor. Acreditamos que nossa pesquisa possa contribuir para uma visão mais ampla e consistente do processo de formação da literatura infanto-juvenil em Língua Portuguesa, assim como para sua contemporaneidade e perspectivas futuras.

PALAVRAS-CHAVE: Literatura infanto-juvenil, Jornalismo e Literatura, Revista $\mathbf{O}$ Tico-Tico, Jornal O Senhor Doutor.

\begin{abstract}
There was a time literature and journalism went on together and literary texts could be found in several publications. There are several studies regarding the relation between those two fields, their confluences and divergences, their authors and their readers. Nevertheless, when the subject is literature aimed at children, little has been discussed. This is a gap to be filled in once there is a vast material to be analyzed. In this article, we propose to present the beginning of our researches for the doctorate, exposing our initial considerations about infantile literature out of the book, circa IXX century and the first decades of the XX century. The Brazilian magazine O Tico-Tico and the Portuguese newspaper O Senhor Doutor are highlighted. We believe our research may contribute to a wider and more consistent view of the process of infantile-
\end{abstract}

\footnotetext{
${ }^{1}$ Doutoranda na área de Estudos Comparados de Literaturas em Língua USP.Orientadora Prof ${ }^{\mathrm{a}} \mathrm{Dr}^{\mathrm{a}}$ Maria dos Prazeres Santos Mendes. 
juvenile literature formation in Portuguese Language as well as its contemporary traits and future perspectives.

KEYWORDS: Infantile-juvenile literature/Children's literature, Journalism and Literature, O Tico-Tico Magazine, O Senhor Doutor Newspaper.

Houve um tempo em que a literatura e jornalismo caminhavam juntos e textos literários podiam ser encontrados em diversas publicações, como jornais, revistas, suplementos e almanaques. Não nos referimos somente a cadernos culturais com artigos, entrevistas ou mesmo resenhas de livros. Referimo-nos a publicação de contos, crônicas literárias e poesias, e até capítulos de romances.

Do século XIX para o XX, ocorreu uma sensível separação desses campos, contudo, ainda nos anos 70, não era raro lermos um conto em um jornal.

Atualmente, esse vínculo praticamente não existe e poderíamos citar algumas possíveis causas: opções editoriais voltadas para o "jornalismo puro", consolidação do mercado editorial, sendo a literatura "desnecessária" nos jornais ou o desinteresse do público leitor, já habituado ao livro.

Alguns poderiam supor que não se deva misturar literatura à imprensa, contudo, as relações entre Literatura e Jornalismo são notórias e amplamente discutidas em nossa atualidade. Como fruto da mútua influência dessas vertentes, vários livros têm sido publicados, podemos citar, como exemplo, o livro Pena de Aluguel de Cristiane Henriques Costa, doutora em Cultura e Comunicação pela UFRJ, que nos apresenta um amplo panorama da produção literária e jornalística no Brasil de 1904 a 2004. A autora cita que diversos autores foram, em suas palavras, "anfíbios", trabalhando na imprensa, mas vislumbrando as livrarias. Há exemplos de escritores que trabalhavam como jornalistas e repórteres sobre assuntos diversos, como política, criminalidade, esportes, cultura, entre outros.

Além disso, com a liberação da imprensa no Brasil no século XIX, diversos escritores encontraram nos jornais não só uma forma de sobrevivência, mas também de divulgação de seus trabalhos. Assim, através das páginas dos jornais, a literatura encontrou uma ampla vitrine. Vale lembrar que muitos dos clássicos nacionais foram publicados em forma de folhetins. Cristiane Costa analisa várias biografias e faz entrevistas com escritores recentes, tomando como ponto de reflexão as intersecções entre os gêneros literário e jornalístico, suas contribuições e possíveis prejuízos. Ela se 
refere a antigos escritores como José de Alencar, Machado de Assis, Coelho Neto, Olavo Bilac, Monteiro Lobato e Graciliano Ramos, até escritores mais recentes como Luiz Rufatto e Marçal de Aquino.

De uma forma simplista, podemos dizer que literatura e jornalismo muito se cruzaram, mais próximos, mais distantes. Segundo Marisa Lajolo ${ }^{2}$, as relações entre Jornalismo e Literatura nem sempre foram harmoniosas, principalmente após o advento da imprensa no século XV, já que essas duas formas de comunicação acompanham a sociedade desde seus primórdios:

Jornalismo e literatura foram uma coisa antes de Gutemberg e outra depois dele, que afetou profundamente o modo pelo qual notícias \& criações estéticas verbais circulavam . Para encurtar uma história que é longa , pode-se dizer que aos mensageiros e arautos sucederam-se os jornalistas, assim como aos jograis e cantadores sucederam-se os escritores. (LAJOLO, 2008).

A autora ainda considera que, apesar de serem diferentes formas discursivas, literatura e imprensa integram o mesmo sistema de escrita, não se confundem, mas são "intercomunicantes". Ela considera que tal intercomunicabilidade se deva ao fato da imprensa ter, durante um certo tempo, financiado a literatura.

Tanto Cristiane H Costa quanto Marisa Lajolo citam o livro Momento literário ${ }^{3}$ de João do Rio, resultado de entrevistas com diversos escritores sobre as influências do jornalismo na literatura. Há opiniões positivas, como a de Olavo Bilac, para quem o jornalismo:

(...) é para todo escritor brasileiro um grande bem. É mesmo o único meio do escritor se fazer ler. O meio de ação nos falharia absolutamente se não fosse o jornal - porque o livro ainda não é coisa que se compre no Brasil, como uma necessidade. (RIO, 1903 Apud LAJOLO).

Ou mesmo divergentes, como a opinião de Coelho Neto:

[O jornalismo], como nunca teve audácia para educar, aceita um trabalho, não pelo gênio do autor, mas sempre de acordo com o agrado do público. Às vezes é perverso. A decadência do teatro é devida exclusivamente ao jornal e aos próprios escritores dramáticos jornalistas (...) Veio o anúncio, o balcão dominou, começaram os incentivos para o trololó. Hoje o público está acostumado e não quer outra coisa. Quanto à literatura que publicamos nos jornais, lembra os livros impressos no tempo do Santo Ofício: não têm o visto da inquisição, mas têm o visto do redator chefe. (RIO, 1903, p. 615 Apud LAJOLO).

\footnotetext{
2 Artigo: "Jornalistas e escritores: a cordialidade da diferença" http://www.unicamp.br/iel/memoria/Ensaios/index.htm acessado em 17/07/08.

${ }^{3}$ RIO, João do. Momento literário,Rio de Janeiro: Garnier,1903.Apud LAJOLO.
} 
Bilac $^{4}$ valoriza a imprensa como forma de divulgação, Coelho Neto critica a sua censura. Podemos considerar que ambos tinham razão, principalmente em um país cujas dificuldades econômicas e repressões políticas foram e são constantes.

Como podemos observar, devido à relevância e polêmicas envolvidas, há vários estudos voltados para a relação entre esses ramos, suas inter-influências, seus produtores e receptores. Contudo, quando o assunto é a literatura destinada ao público infantil, pouco foi discutido. Essa é realmente uma lacuna a ser preenchida, uma vez ser considerável a produção de jornais e revistas para crianças, tanto no Brasil quanto em Portugal, principalmente em épocas em que não havia um mercado editorial destinado a esse público.

A quantidade de textos de literatura infantil, presentes nesses suportes, era abundante e hoje segue os mesmos caminhos da literatura em geral, tende à nulidade. Parece-nos, portanto, que a ruptura entre os diferentes campos, jornalístico e literário, e seus respectivos gêneros, é um fato.

Dessa forma, resta-nos investigar os caminhos percorridos pela literatura infantil fora do livro, assim como as diferenças, se as há, entre os materiais publicados nos jornais e nos livros.

Para nossos estudos, estamos considerando somente os contos e poesias, e não as histórias quadrinizadas ${ }^{5}$. Salvo alguma polêmica, podemos considerar que essas histórias, que deram origem às histórias em quadrinhos, fazem parte da literatura infantil, principalmente pela relação verbal e não verbal, pelos intercódigos tão comuns . Contudo, por uma questão de delimitação de gêneros, optamos somente pelos contos e poesias. Além do que, há consideráveis dificuldades em se definir a literariedade desse material, principalmente no que concerne em seu valor estético.

Em nossas análises, levamos como pressuposto que os textos literários para crianças se apresentam diferentemente nos jornais, revistas e livros, o que implica em uma diferente recepção, assim como intenções e objetivos de escritores e editores. Resta-nos investigar, a longo prazo, se tal pressuposto se concretiza e quais as diferenças observáveis. Para o momento, apresentamos nossas impressões iniciais.

\footnotetext{
${ }^{4}$ É interessante observar que tanto Olavo Bilac como Coelho Neto contribuíram para a formação da literatura Infantil brasileira, além do que encontramos vários de seus textos para o público infantil publicados na revista Tico-tico.

${ }_{5}^{5}$ Consideramos que as histórias quadrinizadas são aquelas formatadas em quadros, com legendas. As Histórias em quadrinhos já apresentam balões com as falas.
} 
No Brasil, podemos citar algumas publicações, conforme nos apresentam Leonardo Arroyo (ARROYO, 1968, pp. 131-151) e Nelly Novaes Coelho (COELHO, 1991, pp. 242-3): O Adolescente (1831), Salvador; O Juvenil (1835), Rio de Janeiro; Livraria dos Meninos (1937), Salvador; Imprensa Juvenil (1870). Assim como outras, presentes no Catálogo da Biblioteca Nacional: O infantil (1895), São Paulo; A gazetinha(1880) ${ }^{6}$, Rio de Janeiro; Revista juvenil(1876), Maranhão; O juvenil-leituras infantis (1892) Rio de Janeiro, A carochinha-Florianópolis-1914; O escolar-Canoinhas1918; O Arrebol-Teresina- 1918-1925; A gazeta-São Paulo, 1929-1950, Suplemento infantil e juvenil-A nação- 1939; Suplemento juvenil-A gazeta. Revistas: O Tico-Tico1905-1962; Lobinho-1939; Mirim; Gibi-1939-1952; Recreio- anos 60 até a atualidade. Almanaques : Almanaque Tico-Tico-1907 a 1958; Vida Infantil.

Como podemos observar, é uma lista extensa. Em todas as fontes pesquisadas, a revista Tico-tico tem tomado maior destaque por sua relevância na formação de gerações de leitores. Assim, a ela nos ateremos.

A revista O Tico-Tico foi publicada de 1905 a 1962. Possuía diferentes seções (semanais e comemorativas), um editorial, a "Lição do vovô", partituras, notícias, entrevistas, anúncios publicitários, seção do leitor (textos e fotos enviados pelos leitores), concursos, romances em folhetins como As viagens de Gulliver de Jonathan Swift e As aventuras de Robinson Crusoé de Daniel Defoe, histórias em quadrinhos, poesia e contos.

No Brasil, segundo Marisa Lajolo e Regina Zilberman, revistas como O TicoTico, 1905, surgem a partir do interesse de uma nova massa urbana consumidora e, conseqüentemente, uma indústria cultural.

O sucesso do lançamento, a longa permanência da revista no cenário editorial, a importância de suas personagens na construção do imaginário infantil nacional, a colaboração recebida de grandes artistas - tudo isso referenda que o Brasil do começo do século, nos centros maiores, já se habilitava ao consumo de produtos da hoje chamada indústria cultural" (LAJOLO \& ZILBERMAN, 2007, p. 23).

\footnotetext{
${ }^{6}$ Em julho de 2009, pude constatar através de pesquisas na Biblioteca Nacional do Rio de Janeiro que vários jornais que receberam o título de " infantil" ou " juvenil" não são realmente dirigidos ao público infantil. Esses termos funcionam como sinônimo para "aprendiz", ou seja, são produzidos por jornalistas aprendizes.Dos nove jornais consultados, apenas "A carochinha" era destinado às crianças. Outros jornais consultados: Echo Infantil (1894), Gazetinha(1882),Tico-tico(1882), A luz(1884),O infantil( 1895), O Guarany( 1900).
} 
Segundo Maria Cristina Merlo (VERGUEIRO \& SANTOS, 2006,pp. 125-9), podemos encontrar os seguintes escritores ao longo de diversas edições de o Tico-tico: Cardoso Júnior, Coelho Neto, Olavo Bilac, Murilo Araújo, Catulo da Paixão Cearense, Bastos tigre, Maurício Maia, Malba Tahan, Trancoso (pseudônimo de Coelho Neto),Malazarte, Wenceslau Semifusa, Humberto de Campos, Oswaldo Orico, Galvão Queiroz, Carlos Manhães, Américo Cllia, Josué Montello, Leonor Posada, Gaspar Coelho e Gustavo Barroso.

Quanto ao material já identificado por nós, podemos citar um conto de Coelho Neto "Quem muito quer tudo perde" publicado na primeira edição da revista Tico-tico de 1905. O conto já fazia parte do livro Contos pátrios de 1904. Verificamos a $27^{\text {a }}$ edição de 1931, cujo título foi ampliado para Contos pátrios para crianças, compondo uma coleção de Educação Moral e Cívica. No livro, as ilustrações são de Vasco Lima, na revista, a identificação está ilegível. Na versão em livro o conto recebe o nome de “ Quem tudo quer, tudo perde".

Apesar do conto ser o mesmo, e sua função didático-moralizante evidenciar-se, a versão da revista apresenta-se visualmente mais leve, mais alegre, o que, de certa forma, destoa com o conteúdo de expectativa e tristeza inicial, uma vez que há um final feliz.

A versão da revista possui imagens chamativas, de tom jocoso. Os traços parecem orientais. A versão do livro, pelo menos essa de 1931, apresenta poucas imagens, com um traço mais tradicional. As ilustrações de ambos os contos são descritivas e narrativas e não são coloridas, com exceção dos contornos vermelhos na revista.

Quanto aos textos, há pouquíssimas diferenças. Parece que a versão em livro, mais "moderna", procurou atualizar o vocabulário, organizar a pontuação, assim como optou por uma linguagem mais metafórica. Por exemplo, ao invés de simplesmente “ raízes expostas", colocou-se "raízes retorcidas à flor da terra".

Quanto ao sub-título “Educação moral e cívica”, podemos considerar que os editores queriam deixar bastante evidente seus objetivos. Já no jornal, tal implicação não é evidente. Podemos acrescentar que ao final do conto, que termina no meio da página, temos uma história quadrinizada estrangeira, intitulada "No circo" retirada do jornal ( revista) "Le bom Vivant" cujo objetivo de entretenimento parece-nos claro. Após ensinar vários truques a seu cavalo, o domador, ao agradecer ao público, leva um 
coice, truque que não havia ensinado. Apesar do mau gosto, pois hoje para nós seria politicamente incorreto, há a intenção de se criar humor.

Com tais reflexões, tiradas apenas desse caso analisado, consideramos que o texto didatizante aparece diluído na revista, ou seja, surge entre outras histórias pretensamente engraçadas, assumindo também o tom de entretenimento. As ilustrações só vêm a colaborar com nossas impressões.

Já no livro, o conto aparece entre outros que também trazem suas lições, são todos contos pátrios para crianças, com o sub-título de "Educação Moral e Cívica".

Pensando nas diferentes formas de recepção que tais textos teriam para as crianças, podemos inferir que o pequeno leitor, ao se deparar com o livro, já sabe, ou intui, que as histórias que lerá são muito importantes para sua formação. Caso ele não tenha essa percepção, os pais ou educadores poderiam escolher esse livro justamente por esse motivo.

Podemos supor que a manipulação do jornal seja maior, uma vez que a criança lê todos os textos para seu entretenimento ou aquisição de informações, e , de certa forma, recebe a lição de moral sem indicações tão evidentes.

No conto "Quem muito quer tudo perde", Coelho Neto defende uma postura de que para se enriquecer é necessário ter paciência e não ser ganancioso. $\mathrm{O}$ autor se apropria de alguns elementos dos contos maravilhosos, mas não segue sua estrutura por completo.

A menina é a heroína da história. Ela segue os conselhos do velho, a quem recebe em sua casa. Não é gananciosa e conquista sua fortuna aos poucos. Aparece como uma boa menina, que ama sua família, pois acaba por salvá-los com suas lágrimas. A mediação, como em conto maravilhoso, se dá pela presença dos dois velhinhos. O primeiro, salvo da chuva, indica para a família onde está o tesouro. A segunda, uma velhinha, também é recebida com atenção pela menina, recolhe suas lágrimas e traz sua família novamente à forma humana. Os pais e irmão são castigados por sua ganância, mas são libertados pelo sofrimento da menina. Como elementos do maravilhoso, podemos destacar o herói, uma pequena menina, que alcança seu desígnio, que não foi bem esclarecido inicialmente, mas que nos parece ser elevar as condições financeiras de sua família. Diferentemente de um conto tradicional, a menina apresentase corajosa desde o início, sendo ela, a menor da casa, a abrir a porta durante a tempestade. Também é independente, pois deixa o velho entrar sem pedir a ninguém. Acaba por receber a ajuda de mediadores mágicos, uma vez que os dois velhinhos são 
seres misteriosos e, principalmente a segunda, apresenta poderes mágicos, chegando a desaparecer inesperadamente. Como obstáculo, ou tarefas, coube à menina levar as barras de ouro, aos poucos, com perseverança para sua casa. Parece-nos uma analogia clara ao grande empreendedor, corajoso, aldaz, mas ao mesmo tempo cuidadoso, sem ganâncias.Essa é uma visão positivista, tão apregoada no início do século $\mathrm{XX}$, como o lema de nossa bandeira, somente a ordem, o método, levará ao progresso.

No exemplar de 25/05/1938 da revista O Tico-Tico, encontramos um outro exemplo interessante, o poema "Represália" de Eustórgio Wanderley".

O autor apresenta um singelo poema, que relativiza alguns valores, principalmente o da menina boazinha e bem comportada.A linguagem coloquial é apresentada entre aspas, indicando que o autor não se sente totalmente à vontade para usá-la.

Com a opção de um eu-lírico feminino, o autor nos apresenta Lili, uma menina de seis anos que diz que não convidará os pais para seu casamento, já que não a convidaram para o deles. Na terceira estrofe, o eu-lírico feminino diz:

\footnotetext{
Não me julguem vingativa, Mas também não sou santinha.... Quando "me fazem alguma" Eu "tiro minha casquinha"
}

A revista O Tico-Tico reinou absoluta até os anos 30. Em 1934, Adolfo Aizen fundou o Suplemento Infantil (posteriormente Juvenil) no jornal A Nação, no Rio de Janeiro. Esse suplemento foi um sucesso instantâneo e inaugurou uma nova fase na divulgação das histórias em quadrinhos no Brasil, a partir do modelo norte-americano. No mesmo estilo, surge O Globo Juvenil, das Organizações Globo. Esse foi o início da decadência da revista O Tico-Tico. Segundo Waldomiro Vergueiro:

De repente, os personagens ingênuos e bem intencionados da revista passavam a ser substituídos no gosto popular por intrépidos desbravadores de novos mundos, homens mascarados ou seres superpoderosos. Foi um choque. (VERGUEIRO \& SANTOS, 2006, p. 206).

\footnotetext{
${ }^{7}$ Eustórgio Wanderley nasceu no dia 5 de setembro de 1882, na cidade do Recife, PE, onde estudou e morou durante quase toda sua vida. Adulto, dedicou-se ao jornalismo, atuando no Diário da Manhã e no Jornal do Recife. Academia de Letras de Pernambuco. Compositor de músicas
} 
O autor acrescenta que a revista até tentou competir com as novas publicações, mas para isso perdeu seu bom nível e acabou por perder espaço. Dos anos 30 aos 40, tentaram se equipar às novas tendências das Histórias em Quadrinhos, mas aos poucos retornaram aos seus propósitos iniciais.

Além da concorrência, Waldomiro Vergueiro aponta outros fatores para o declínio da revista e sua extinção: Mudança dos gostos do público, mais adepto às aventuras das HQs, o surgimento da Televisão e dos desenhos animados e, finalmente, um novo mercado consumidor: os adolescentes.

Como qualquer obra de tanto alcance, a revista $\mathbf{O}$ Tico-tico está impregnada de ideologias que retratam o período histórico em que viveu. Nacionalismo e um didatismo-moralista são encontrados em diversos textos. Principalmente nos anos 30, observa-se um firme propósito de influenciar o desenvolvimento intelectual das crianças brasileiras, a partir de concepções positivistas. Na edição de 25 de maio de 1938, por exemplo, encontramos ao rodapé o seguinte conselho: "Menino, a ordem é a primeira lei do céu! Sem a ordem, sem método, nada conseguirás".

Segundo Waldomiro Vergueiro, os responsáveis pela revista defendiam um tipo de revista que pudesse colaborar para a produção de adultos pró-ativos, que acreditariam na força do trabalho e participariam do capitalismo em ascensão e acrescenta que o público era formado por crianças da classe média, tementes a Deus e respeitadoras dos valores pátrios.

A revista, posteriormente, tornou-se objeto de leitura de todas as classes sociais, mas manteve valores das classes dominantes, apresentando diversas vezes situações de extremo preconceito racial e social. Seu modelo didático-pedagógico permaneceu até o fim.

Em Portugal, até os anos 60, além de O Senhor Doutor, que destacaremos a seguir, outros jornais para crianças surgirão como $\mathbf{O}$ papagaio, $\mathbf{O}$ mosquito e $\mathbf{O}$ diabrete, contudo, os comics, material importado da Kings Features, passarão a dominar o mercado, o que se denominará a "americanização da imprensa infantojuvenil”. Assim, esses jornais passam a perder sua força, sendo substituídos por revistas somente com histórias em quadrinhos.

No jornal O Senhor Doutor (1933), além de diversos contos, já se podiam encontrar várias dessas histórias em quadrinhos, com temas e personagens americanizados (provavelmente compradas e traduzidas), assim como algumas nacionais com personagens de nomes bem curiosos como Zuca, Azruca e Bazaruca, 
por exemplo. Esse jornal surgiu em pleno regime Salazarista, o qual, segundo Natércia Rocha, influenciou a formação escolar e cultural das crianças e jovens, pois só eram editadas obras de caráter histórico com o objetivo de exaltar os valores pátrios e o Salazarismo.

As análises iniciais que já fizemos do conteúdo do jornal O Senhor Doutor já compravam as afirmações de Natércia Rocha. Contudo, podemos encontrar exceções, textos de imenso valor estético, como os contos de José Gomes Ferreira que deram origem ao livro As aventuras de João Sem Medo, ${ }^{8}$ textos que inclusive condenam o sistema vigente e não foram censurados, vale dizer que por mero descuido e incapacidade, para não dizer ignorância do censor, uma vez que todos os textos tinham que passar pelo crivo da censura.

Ainda podemos acrescentar que a expansão do rádio e do cinema, assim como jornais e programas radiofônicos para crianças, já trazia consigo a influência norteamericana, principalmente nos filmes e nas histórias em quadrinhos (bandasdesenhadas, em Portugal). Há propostas de novos temas para a época como aventuras de cowboys, índios e piratas. O que ocorreu também no Brasil.

Ao ler o jornal O Senhor Doutor, "um amigo que diverte, educa e instrui", podemos perceber um público ideal pequeno burguês, cercado por ideais moralistas e de valorização dos ideais salazaristas. Encontramos histórias em quadrinhos, contos e orientações de como se comportar, ser "uma boa criança", assim como observamos na revista $\mathbf{O}$ Tico-Tico.

Logo na primeira página do primeiro número, temos uma história em quadrinhos intitulada "O império português e suas ações na África: Um episódio heróico de nossa acção em África: O escudo". Nela, o império é glorificado, assim como os maus tratos aos nativos é banalizado. O negrinho Pete, ao ser "salvo" pelo capitão Albuquerque, torna-se seu maior defensor. Como podemos observar, a imagem de país "multirracial" e compreensivo com as diferenças quer ser passada.

Ao defender o menino de seu agressor, "o cruel colono", o capitão é chamado de herói. Ser solidário, uma atitude mais do que esperada de um ser minimamente humano, é dimensionada e exageradamente valorizada como um grande feito. Seria como dizer: "Vejam, crianças, como o exército português é benevolente e protege os

\footnotetext{
${ }^{8}$ Livro analisado na dissertação de mestrado "Denúncia da exploração humana através de carnavalização". Menna, Lígia R M Cavalari.2003.
} 
pobres negrinhos africanos!" Consideramos esses fatos de extrema hipocrisia e crueldade.

Em outras partes do jornal, podemos observar o moralismo e a distinção clara entre os gêneros. Como exemplos, encontramos "A página das meninas" em que se ensina a confeccionar florzinhas de feltro para a mãezinha, fazer doações e não ser uma menina muito falante

Para os meninos, instruções de como montar uma plataforma flutuante para aterrissagem de aviões transatlânticos. A cada exemplar, o menino terá uma parte da plataforma que deverá ser montada com cartolina e goma arábica. Temos um período entre guerras, no qual os arsenais bélicos são valorizados. Vale destacar que todo o material do jornal passava pelo crivo da censura.

Constatamos que, ideologicamente, o jornal português e a revista brasileira se equiparam, pois sua proposta didático-pedagógica para uma classe privilegiada torna-se evidente, assim como a construção de um público ideal. Ao estudarmos as produções literárias dessa época, já encontramos essas características, ou seja, não foi nenhuma novidade, era o que esperávamos. Contudo, o que procuramos é o que difere, é o que enriquece, assim como os textos de José Gomes Ferreira, que mesmo se mostrem representantes de certos condicionamentos morais, ainda são esteticamente ricos.

Ao iniciarmos nossa pesquisa, ficamos, de certa forma, inconformados de não haver mais literatura nos jornais. Hoje, diferentemente, julgamos que a ruptura dos gêneros, ou campos jornalístico e literário é extremamente natural. Cada um assumiu seu espaço, com objetivos aparentemente bem definidos, ora entreter, ora informar, ora educar,ora provocar.

Acreditamos que o material literário destinado ao público infantil encontrado no jornal O Senhor Doutor e na revista O Tico-Tico, assim como outros que venhamos a encontrar, são de extrema importância para se construir um amplo panorama da literatura infantil publicada na imprensa como forma de averiguarmos as interinfluências ocorridas, principalmente as mudanças apresentadas entre os textos publicados em jornais e revistas, daqueles publicados em livros.

Nossa pesquisa poderá contribuir para uma visão mais ampla e consistente do processo de formação da literatura infanto-juvenil em Língua Portuguesa, assim como para sua contemporaneidade e perspectivas futuras.

\section{REFERÊNCIAS BIBLIOGRÁFICAS:}


ARROYO, Leonardo. Literatura infantil brasileira. São Paulo: Melhoramentos, 1968. BILAC\& NETTO. Olavo e Coelho. Contos pátrios.-para crianças. 27 ed. Francisco Alves,Rio de Janeiro, 1931.

COELHO, Nelly Novaes. Literatura infantil: teoria, análise e didática. 6.ed. São Paulo: Ática ,1978. (Fundamentos,87)

. Panorama histórico da Literatura Infantil e Juvenil. 4.ed. São Paulo: Ática ,1991.(Fundamentos, 88)

COSTA, Cristiane. Pena de Aluguel. São Paulo: Cia das Letras, 2005.

LAJOLO, ZILBERMAN, Marisa e Regina. Literatura Infantil brasileira, história e histórias. São Paulo: Ática, 2007.Série fundamentos.

ROCHA, Natércia. Breve história da literatura para crianças em Portugal. Lisboa: Biblioteca Breve, 1992.

VERGUEIRO \& SANTOS, Waldomiro e Roberto. O Tico-Tico 100 anos-Centenário da primeira revista de quadrinhos do Brasil. Opera Graphica: São Paulo, 2006. ZILBERMAN, Regina(org) A produção cultural para crianças. Porto Alegre: Mercado Aberto, 1982.

\section{REVISTAS E JORNAIS:}

Jornal O Senhor Doutor, Lisboa, de 18 março a 30 setembro 1933. Microfilme. Biblioteca Nacional de Lisboa.

Revista O Tico Tico, Rio de Janeiro, Publicação D’ Malho. Exemplares avulsos de 1911,1938,1954. Biblioteca Monteiro Lobato.

Almanaque Tico-Tico-1947,1952,1953,1954,1956. Biblioteca Monteiro Lobato.

Revista Tico-Tico- $\mathrm{n}^{\circ} 1$ de 11 de outubro 1905 - Encarte in VERGUEIRO \& SANTOS, Waldomiro e Roberto. O Tico-Tico 100 anos-Centenário da primeira revista de quadrinhos do Brasil. Opera Graphica: São Paulo, 2006.

\section{REFERÊNCIAS ELETRÔNICAS:}

ZILBERMAN, Regina. Artigo: "Jornalistas e escritores: a cordialidade da diferença" in Memória da Escrita http://www.unicamp.br/iel/memoria/Ensaios/index.htm Acessado em 17/07/08

Fundação Biblioteca Nacional http://www.bn.br/portal/ Acessado em 15/07/08 